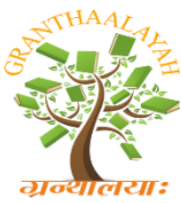

Social

\title{
INFORMATION TECHNOLOGY INTEGRATED EDUCATION, A HARD ROAD TO TRAVEL FOR LAME DUCKS: BLENDED INSTRUCTIONAL DELIVERY, POTENTIALS FOR LEARNING AFFORDANCES FOR ELT STUDENTS, UNIVERSITÉ FELIX HOUPHOUËT BOIGNY, CÔTE D'IVOIRE
}

\author{
Sidiky Diarassouba *1 \\ ${ }^{* 1}$ Université Felix Houphouët Boigny, UFR-LLC, Département d’Anglais, English Applied \\ Linguistics
}

DOI: https://doi.org/10.29121/granthaalayah.v5.i1.2017.1907

\begin{abstract}
Increasingly, matters relating to formal education have been moving away from secular formats to more technology-oriented ones, such as online and various distance teaching and learning networking arrangements. While advanced educational systems have been being carried in a general momentum towards these newer information technology integrated instructions, the vast majorities of countries worldwide lag behind. Such ones are those from the developing world, in general, and particularly most African countries. Among the main reasons, as it appears the culture of these newer ways of doing education and issues regarding the external environment are prominent candidates. Consequently, it is hard for all those countries to actually be on board. However, there seem glimpses of hope to benefit from advances in technological innovation even in underprivileged areas. To what extent can some forms of information technology be incorporated in education, and to what avail? Such was the central questioning which this research project tried to address. It turned out that forms of blended instructional formats were viable solutions given the many teaching and learning affordances they embody. A major contention that transpired from this study was that, based on their particular circumstances, instructors would be much better off considering the use of some forms of integration of new technologies in their instructional design than no integration at all, pending better auspices.
\end{abstract}

Keywords: Information Technology Integrated Education; Blended Instructional Delivery; Affordances; ELT Teaching And Learning; Virtual Learning. 
Cite This Article: Sidiky Diarassouba. (2017). "INFORMATION TECHNOLOGY INTEGRATED EDUCATION, A HARD ROAD TO TRAVEL FOR LAME DUCKS: BLENDED INSTRUCTIONAL DELIVERY, POTENTIALS FOR LEARNING AFFORDANCES FOR ELT STUDENTS, UNIVERSITÉ FELIX HOUPHOUËT BOIGNY, CÔTE D'IVOIRE." International Journal of Research - Granthaalayah, 5(1), 332-354. https://doi.org/10.29121/granthaalayah.v5.i1.2017.1907.

\section{Introduction}

Information Technologies, as intrusive as the octopus, have invested all the areas of the socioeconomic, political and educational life, among others. The digital civilization spares nothing. School has been largely influenced by newer technologies from about the 70s, when first attempts to distance education were made (Berge, 2001)

Vast research in the area of information technologies integrated education has pinpointed various and varied merits and benefits. Further, not only have research endeavors shown that there is a wide use of information hardware gadgets associated or not with software, but also the positive impact of the foregoing has been established by the overwhelming majority of studies that have been conducted, thus far.

However in this global village that is our world, education digitalization has not been evenly distributed among school boards and educational systems all over the world. As a matter of fact, the underprivileged of the 21 st century seem to be literally excluded from this fertilizing and bubbling blossoming. The reasons that seem to keep them from the " starting block " of this technology highly desirable adventure include technological, structural and institutional arrangements in training institutions in Third World countries in general, and especially in subSaharan Africa, which is why initiatives with respect to the digitalization of formal education have often failed. By way of consequence, these countries are hard put to join in the digital chorus.

Now should educational systems in these countries be regarded as outcasts of the digital age? In other words, Is there a way out to take advantage of the present technological advances in our school, in one way or another?

There would seem some space to manoeuver that key actors, especially teachers and administrator, could exploit, based on the types and forms of technological applications that are in force in daily social life, i.e., email, chat rooms, mobile laptops, iPods, mobile phones and smartphones that most learners also have access to just like their fellow citizens. What types of technologies, on the one hand, and what applications of these technologies on the web, on the other hand, could be integrated in instructional deliveries? What could be hoped for students learning wise?

Given the circumstances, a form of blended delivery format seemed worth considering. Thus, it dawned on me to conduct a form of integration of information technologies in L3 (third year students) course and observe how things develop from an ecological perspective. 
An ecological approach stresses the fact that language learning is emergent in that everything that is eventually acquired emerges from a participatory scheme embedded in social intercourses (van Lier, 2004; Lantolf and Thorne, 2010).Thus, learning is rooted in the history, experiences, and sociocultural events tributary to social participatory practices of learners with other social partners (van Lier, 2000, Lantolf \&Thorne, 2009). An Ecological Approach necessarily promotes life-like communication. Therefore it seems most appropriate to make a real difference in foreign language education.

\section{Sociocultural Theory as a Theoretical Framework}

Sociocultural theories pay a large tribute to Vygotsky's "Social Development Theory" which has it that learning and development are socially and culturally situated in essence. Its contribution to teaching in general and particularly language teaching is recognized worldwide. Sociocultural theory, according to Aimin(2013: 162),

....is a theory about the development of human cognitive and higher mental function. The theory argues that the development of human cognitive and higher mental function comes from social interactions and that through participation in social activities requiring cognitive and communicative functions, individuals are drawn into the use of these functions in ways that nurture and "scaffold" them.

Learning is social because anything that one eventually learns is first presented, directly or indirectly (incidentally) in social intercourses by the More Knowledgeable Other (MKO) (Vygotsky, 1978). From the foregoing a number of constructs are brought to bear, such as regulation which falls into three types (object, other and self [Lantolf \& Thorne, 2009), internalization involving inter-psychological and intra-psychological processes (Behroozizad, Nambiar, \& Amir, 2014), the zone of proximal development (ZPD), verbal thought, activity theory (Engestrom, 2001), and mediation which unites all of them. Mediation in its turn is dependent on the use symbolic tools, or signs for cognitive and material activities to occur.

In the realm of language education, in particular, learners 'downright engagement in real life tasks that are meaningful and interesting to them serves as a catalyst for learning and development (Pica, 1993; Roebuck, 2000-Lantolf). For their franc and deliberate involvement in activities that are prompted by the task they end up learning not only the tool of mediation (semiotic tools, i.e., language) but also the process which they will be able to implement in subsequent tasks on their own (Ellis, 2000; Fahim and Haghani, 2012:694).

Sociocultural theories in general "[... ] Provides the psycholinguistic framework for a number of approaches (e.g. task-based learning and collaborative learning)" (Dongyu and Wanyi, 2013, p. 169). Actually, they magnify the role of interactions as the ferment of social life but also as the gateway to learning in general.

The ecological approach encourages social interactions in which environmental possibilities or opportunities that become handy in social intercourses should be improved to boost up learning. This entails multilayered and multifaceted interactions among learners with numerous 
ramifications that are brought to bear. Among other consideration, this would seem to testify why the ecological Approach is grounded in sociocultural theories.

\section{Literature Review}

In this section, I reviewed the literature on Information Technologies, particularly in light of their integration in education. Then, I tried to survey major takes of scholars in the area of blended teaching and learning instructional formats. Furthermore, my last concern was understanding ecological approaches to human development in general, and language learning in particular. It was hoped that insights gained from the literature in the above areas would allow for broaching the present study under much favorable auspices.

\section{Information Technologies}

The great strides in the advances of newer means of communication have changed the way people live on this planet, including the way education is done, especially in educational systems of advanced economies. Information integrated education, quite a newer concept, entails the use of PC multimedia networking sustained by digitalization functions, such as audiovisual stimuli supported by fast handling and convenient connectivity for secure and fluid communication (Singh \& Reed, 2001; Xu, 2016). The integration of the gambit of technological gadgets from OHPs, PC, and video-projectors through iPods and iPads, to smart whiteboard and smart projectors, either fixed or mobile partially or fully interactive allow for prodigious things inside the classroom (Berge, 2001; Xu, 2016).

Applications of these technological wonders are also numerous and varied. A major advantage is that learning becomes thus fun, entertaining, relaxing, which increases motivation and engagement (Anderson \& McGreal, 2012). The corollary is that learning seems much better (Castle, 2010), beside other benefits that accrue to both the instructor and the learners. For instance, some studies have revealed that teachers gain professional growth while student are said to have higher sense of learning thanks to the range of learning avenues they are presented with on the web and the tremendous wash-back, such as the development of critical mind and problem solving capabilities, abilities and capacities (Xu, 2016; Donnelly, McGarr, \& O’Reilly,2011).

In a certain way, all major relations that are brought to bear in the didactic triangle - the curricular, the pedagogic and didactic - are dealt with interactively and wholesomely. However, information technologies integrated education is highly dependent on favorable environmental factors, hardware, software and quality networking facilities, and this is what is often problematic.

\section{Blended Formats}

Blended instructional formats, which stands for a combination of traditional teaching format (e.g., teacher-fronted) and the use of some web services for instructional purposes, have been implemented in some educational systems around the world. Blended formats abound, such as 'offline and online learning', 'work and learning', 'synchronous online', 'asynchronous format', 
to cite only these (Lim, Moris, \& Kupritz, 2007). The reasons for using these formats are often varied and numerous. However, the most recurring one is when environmental factors do not allow for full online application, types and applications of information technologies come into play (Lim et al., 2007). In Reece and Lockee's (2005) thinking, blended formats may allow for doing away with perceived weaknesses of full online instruction, such as the lack of instructorlearner interaction, which is still regarded as foundational in education and learning in many cultures around the world (Berge, 2001; Lim et al., 2007).

Blended formats have helped achieved substantial results by drawing on the strength of both traditional and the virtual instructional deliveries.

Literature in the field is convergent on the fact that there is a fairly important cognitive gain that accrues to both learners and instructors who interact with or through the web materials and applications in education (Singh \& Reed, 2001), which makes Information Technology Integrated Education highly appealing.

\section{Predecessors to Ecological Approach}

Education always has been characterized by a bewildering restlessness as evidenced through multiple voices and reforms when it comes to methods or approaches to teaching and learning, on one hand, and programs and curricula on the other. Let us recall just a few.

Grammar translation (GT), the oldest method, which emphasizes literal translation has been around since the Latin and Greek era. However, in light of new finding in the field of education, it lost ground to the Audiolingual method (ALM) from the 1960s onward. It came at the hay days of Structuralism and behaviorism, under the leadership of Ferdinand de Saussure et Skinner, respectively. The views of these scholars on language were convergent in a sense: language was finite and what counted most was the mastery of chunks of the system in order to build 'the language'. Thus, the chunks would be learned by dint of sustained repetition, and then adding up all assimilated chunks would yield the language.

It is noteworthy that GT and ALM, even though they are different in nature, they both, nevertheless, stress the psychological processes of the learner, supposedly operating in isolation. Further, language usage, more so than language use, seemed to be in the forefront of the act of education (Yates \& Muchisky, 2003). All the above ended up starching the head of learners with knowledge that is unusable (Larsen-Freeman, 2000; Tomasello, 2003). Language is first and foremost a sociocultural artifact for communication purpose. However, learners proved incapable of using the language for this social purpose, even after years of language education, which recalls the notion of inert knowledge (Whitehead, 1929).

At the close of the of 1980s came to the fore Communicative Language Teaching (CLT), which may been the result of the convergence of a number of theories or philosophical movements, namely functionalism, Poststructuralism, Postmodernism, besides Dell Hymes research on communicative competence. In any case, all the above rejected the major views espoused in structuralism and behaviorism. Rather they emphasized the use of foreign or second language as the most appropriate means for language acquisition (Halliday, 1994; Martin, 2011). 
The educational community had high hope in this approach, but things did not turn out as expected for a number of reasons, including the neglect of the context of instruction (Breen, 2006; Gilthrow \& Colhoun, 1997), an undue emphasis of the system still, due to economic pressure that turned English, in particular, into a commodity (van Lier, 2004). In the same order of things, Lantolf (2000) wrote language is then, "a commodity that is accumulated by the learner and the mind construed as the repository where the learner hoards the commodity" (155). This recall Freire (1997)'s Banking model.

Dissatisfaction with CLT prompted the community to look for new ways of doing language education. There were talks about Post-method, In-Method and Complexity Theory (Mahmoodzadeh, 2012). The first advocated thrashing methods, and advocated instead reflexive thinking, action research, and the 'self-reliance' of the teacher among other considerations(Bax, 2003; Richards \& Renandya, 2002), while the second suggested using methods, but moderately, intelligently and wisely (Ellis, 1994; Nishino, 2008, Larsen-freeman, 1999). As for the last, it calls on the community of educators to become aware of the true nature of language, language teaching and learning which is chaotic, complex, dynamic, and adaptive and behave accordingly (Larsen-Freeman, 2007)

Overall, misleading beliefs, assumptions, and perceptions regarding ELT, in particular, over years, have ended up fating the whole process of language learning. That is why, people have been earnestly looking for approaches that seem more compelling in terms of language learning. An ecological approach, which emphasizes social participation in real social life like context as key to learning, seems more enticing and appealing in more than one respect.

\section{Ecological Approach}

An ecological approach thrives on social opportunities including symbolic and semiotic ones that are out there in the social environment, both physical and psychological, referred to as affordances (van Lier, 2000) and which are selectively and parsimoniously exploited by learners, based on the needs, interests, the motives at a given point in time (Mahmoodzadeh, 2012; van Lier, 2004). Therefore, not only does an ecological approach serves as a layer for language acquisition, but it also does so as a functional springboard for real language use in society for true communication purposes whose meaning and bearing reside in sociocultural underpinnings(Hopper, 1998; Martin, 2011). So in a sense, an ecological approach is a newer model of social cognition, environmental in essence, as opposed to the cognitive models that have been suggested over years. One may venture to say an ecological perspective on language learning looks at long standing concepts of SLA in a novel way, in an innovative framework.

From an ecological perspective, learning is essentially outside-in, as the mind is necessarily mediated by verbal communication with others (Lantolf, 2008; Baktin, 1981). Further, mental functioning and psychological processes are both mediated and ingrained in cultural and environmental affordances tributary to the history, on one hand, and experiences embedded in other social partners and also local denizens including physical and mental environmental assets, on the other (Kramsch, 2008, van Lier, 2010). This approach earnestly calls for the restauration of human and natural ways of learning, in which intakes are contingent on the particular interest, 
need, and motive of the moment (Kuuti, 1996; Lantolf \& Thorne, 2009). As such, it holds promise of success.

The intention of the researcher was to observe learners left to their own devices and who were engaged in a community of language practice online from an ecological approach, on one hand and to see how things developed in terms of learning, on the other.

\section{Methodology}

In this study, the instructional endeavor had for a main focus an asynchronous online activity. A thread set in motion the activity which included a number of interludes such as critiquing writeups produced by participants themselves, giving feedback on the critiques and also evaluating the online activity itself. The instructional scheme included four phases (1-4). A group e-mail was created to be used exclusively in the context of the course. The instructor and all participants used it as a virtual board for posting assignments and completed tasks. This was a way to better channel the resources and substance of the activity. Various types of data were collected by means of corpora built up through activities in various phases of the task.

\section{Participants}

The population was made of third year students. An intact group of 35 students from the ESP course was the sample of the study. The sample was purposeful (Wiersma, 2001).

\section{Procedure}

Phase 1: it was twofold. For the first task, the subject was worded as follows: "What do you mean by developing a curriculum in the context of ESP?" To answer this question the students were asked to identify one or more sites related to the subject on the web and write a page to share with the rest of the group one week later. This was meant to be a preparatory work for the second task which was concerned with the asynchronous online task based on the following prompt, "What does problematizing a situation in the development of an educational program such as ESP mean?" Participants had to produce a 5-line write-up to be posted on the virtual platform of the common e-mail address.

Phase 2: After forming psychological groups of 5 participants each, I asked them to critique the texts of their peers from their home group in terms of relevance of ideas in the write-ups, critical disagreements, pertinence of arguments put forward, etc., but always bearing in the thread.

Phase 3: Participants were asked to respond to criticisms on their texts by expressing their agreement or disagreement or making some clarifications or supplementing answers, among other considerations.

Phase 4: Participants rewrote the answer to the prompt - the thread to the asynchronous activity, bearing in mind insights that had been gained from exchanges that had taken place.

\section{Data collection}

Activities at each phase, such write-ups, critiques, feedback and the evaluation of the asynchronous activity itself were the main means for data generation. 


\section{Data analysis}

Two types of analysis were carried out. Content analysis supplemented with a microanalysis. The microanalysis, which is fundamentally a content analysis focused on the evolution, moment by moment, of the ideas/views of participants (Miles \& Huberman, 2004) with respect to the subject that served as a thread in the asynchronous activity.

\section{Results}

The results include four sections, entitled Phase $1,2,3 \& 4$

I. Phase 1: Thematic Units that transpired in the write-ups of Phase 1 are laid out below.

A. Investigation of the problem: Reconnaissance; Central questioning that address the Where, What, Why, and How of ESP; and Needs assessment,

B. The Nature and definition of ESP,

C. Issues Relating to the content of an ESP course: Language use, function and skills; materials

D. ESP methodology: Learner-centered; functions and skill-centered; An approach to ELT

E. Origin of ESP

F. The structure and components of a course design

G. Course outline and syllabus

H. Motivation

I. Learners expertise in the field to value

J. Evaluation

A survey of the write-ups from Phase 1gave ten thematic units overall.

II. Phase 2: This part is concerned with the critiques on the first write-ups. The most outstanding statements are grouped here in 3 categories: A) Sound critique, B) Impertinent critique and C) Insights.

\section{A. Sound critique: statements or critiques that were found pertinent}

1) "I agree that problematizing consists in investigating the situation by asking the right questions to the right parties to gather the right information for a course design."

2) "Yes, you are right. I think I did something else. I need to be more focused."

3) "I think I misunderstood the question. Yes, it seems to be the procedure that goes into designing an ESP course."

4) 'I forgot to talk about learners' assessment as a crucial point in problematizing. Tibo's question made me realize that"

\section{B. Impertinent critiques: statements or criticisms that were judged disputable or on which} there was disagreement

1) "Your criticism does not seem right. By the question 'Who, Where, What, and Why', I mean to problematize. These questions will allow me to collect appropriate data"

2) "Do you think we should talk about instructional methods here? I do not share your view" 
3) "You are more concerned with defining course design than with what we understand by "problematizing a situation."

4) "Are you saying that ESP is about mastering subject matter? I think this task is about designing a course, right?

5) "Bolo, you put more emphasis on the outcome rather than on the course design itself."

6) "This task is not about the historical development of ESP. What does problematizing means? This is what we are concerned with

7) "I don't know, but why are you talking about ESP as an approach? I'm confused"

\section{Insights gained from peers: things found to be enlightening}

1) "Rick's 'relevant questions' that allow for problematizing the overall situation help me understand the question."

2) "Critiquing and sharing information help me understand so many things regarding ESP beyond the present question, such as it is an approach to ELT, it is learner-centered in essence, that awareness of needs makes ESP different from other areas of ELT, etc."

3) "Nico's comments made me realize that the course designer explores, probes the context through interviews and observations, among other considerations."

III. Phase 3: The evaluation of the online asynchronous activity yielded various comments and statements which are organized around 4 sections: A) perceived benefits, B) difficulties, C) Time not ripe for technology integration.

\section{A. Perceived benefits of asynchronous activities:}

1) Collaboration-rich activity: there were lots of interactions among participants which help set up a community of practice in which language was a mediational tool. Below are a few statements that manifest the fact:

a) "The way the activity was organized made people interact. So it encouraged collaboration between each other."

b) "Each of us had to say something in order to put our classmates on the right way because we did not have the same perceptions and the same way of understanding things. This particularly helped me a lot"

c) "It allows us to get a feedback from our classmates and to save time."

d) "Generally speaking, from the second step of the online assignment the activity was very exciting in terms of sharing and discussing our views."

e) "This activity makes everyone active participants because it gives everyone space to have their say."

f) "We share a lot among ourselves on important points regarding the task, such as the definition of 'problematizing' or the concept of 'course Design', to cite only these."

2) Learning: learning translate into a form of development, as one moves from a stage where we did not know to one where we do

a) "We learn from our peers since we have the possibility to compare our work and improve ourselves."

b) "After analyzing my classmate's reactions, I understand in a much better way who an ESP course designer is, and what makes him different from instructors in general." 
c) "Various uses of computer got developed through the online activity which helps me improve upon my computing skills."

d) "The experience I acquired has prepared me to make my way out in the next online activities I will face".

e) "I found it very interesting to get engaged in this online activity. From the second stage, the reactions of the members of my group helped me sized my understanding of the ESP course design issue."

3) Environmental affordances: in the process of the activity they came across a number of opportunities that they put to good use.

a) "I learnt a lot from this activity, not only from my team but from others' works online."

b) "I was able to use other online resources, such dictionaries, translate from google to improve on my write-up."

c) "I was in doubt when some of friends wrote contradictory things regarding 'ESP as an approach to ELT'. On google I was able to visit other areas, which helped me a lot because the information that I got from there clarified things to me. 'ESP is not a product but an approach'."

d) "Apart from peers there were also online sources where I got information to answer the question. All this encourages me to surf the web which is like a gold mine."

4) Absence of human presence: in the virtual world learners are left to their own devices

a) "It also helps us to do our exercises freely without the presence of a supervisor."

b) "This activity gives the space to everyone to have his say, and not be passive because of shame or fear the way it is when we sit in groups and work."

c) "There is no pressure. We take time to read peers' comments which were very instructive and informative. But sometimes we do not know what to do when there are so many opposing views. In this case, the teacher's present is important."

\section{5) Building confidence and motivation:}

a) "It helped me to check if I deserve to be part of the beautiful and challenging field of Applied linguistics. When I saw the production of the lead of the group and Beyo's it helps me become more confident than I was before the activity.

b) "The online activity was helpful in many ways, especially it created a kind of confidence and motivation in me which I do not usually have. So it helped me learn more than in classroom"

c) "This activity increases critical learning and self-reliance";

d) "It is less stressful, so I feel motivated"

6) Time and energy saver:

a) "The online activity, besides making learning more interesting and better, it saves time and money, since I don't have to meet our friends physically."

B. Difficulties experienced: This is about shortcomings they faced in the process of the asynchronous activity. Ten people on the whole were unable to post their contribution at one time or another during the activity.. 
C. Time was not ripe for including this kind of activity in instruction with larger population: participants pointed out that technical problem related to connection issues to the wide web are serious impediments to the implementation of online activities.

IV. Phase 4: This phase consisted of two sections, (A) \& (B). (A) includes 2 thematic units ( $1 \&$ 2 ) that were revealed by perusing write-ups in Phase 4 . The first includes two components while the second only has one (Cf. below). In (B), results of the analysis of selected texts are laid out (Cf. under "B").

\section{A. Assessing write-ups for thematic units or rubrics}

1. Course design rests on investigation

a) Feel the ground

b) Identify major parties or sites and assess them

2. Design the course based on collected information

The above shows two rubrics $(1 \& 2)$. Rubric 1 includes 2 thematic units.

B. Individual assessment: 10 selected texts from Phase 1 and 4, 5 each, underwent a microanalysis. The results are presented below. The participants (authors) went under fake names, such as Alisto, Crocozi, Crocoza, Titipo and Yawolo.

Crocozi and Titipos' are evasive and hedging. The former mentioned the role of course design in ESP instruction (L. 1-3), then the structure of a course as reflected in "aims, objectives', etc., lines 3 through 4, Appendix A, text 1 (A.A-1, L. 3-4). Then the latter's text is just wordy and vague (L. 1-3). Then lines 4-5 where he wrote "ultimate goal," "selection of material," "syllabus," Appendix, A, text 2 (A.A-2) are just dangling. It seems clear and unequivocal that the main question was not addressed in these texts.

Alisto and Crocoza mentioned a number of notions or concepts that are related to ESP or even to course design. However, they did not address the issue either. In Alisto's, for instance, one can read about end results of ESP instruction as in " to be operational in their domain" (L.2), then "materials, methods, learning tasks according to specific needs" (L. 3), all of which come in a haphazard way (A.A-7). Similarly, Crocoza wrote about the outcome of an ESP course ". . to be efficient in their field"(L. 1), "needs analysis" (L. 4"),"asking question" (L.3), and "good outcome" (L. 5), in a loose and disorderly fashion (A.A-3). These texts look unconnected and jumbled up.

The last text by Yawolo is simply astray. Yawolo talks about a number of things that may be related to general issues of ESP, i.e., dos and don'ts in ESP, "ESP is more focused on language in context than on teaching grammar and language structures" and "the learner must approach the study of the target language through a field that is already known and relevant to him" (L. 24). But overall, he missed the whole point (A.A-4)

The five texts show no straight forward link with the core issue of the thread. We may venture to say that they are about everything except the main question they were supposed to address. Now, How do the write-ups in Phase 4 fare with respect to the prompt? 
In contrast, All of the texts $(\mathrm{N}=5)$ produced by the same people show a clear and unequivocal departure from the vagueness, the confusion, the overstretched ideas from Phase.

Alisto, in line 3 (A.B-2) wrote "Investigate to have a clear-cut idea. . .he/she problematizes the situation," which is closer to the main idea much more so than statements in the Phase 1 text. Likewise, Crocoza (A.B-4) mentioned “. . .Needs analysis-target and learning needs. ..” (L.3-5), which are also quite close to the central thinking. In the same way, Yawolo indicated that "... needs analysis is crucial. .." (L.2) and "Problematizing. . provides needs for course design" (L.4-5, A.D-2). Then Titipo has it that problematizing entails a number of questions, "Who is the learner? What to integrate in the program? What is the context? And What is the time allotted" (L. A.C-2). This seems to show that he was able to gleam the substance of the question, now. As for Crocozi, he said that it "Calls for where to begin, why, how, what content and materials. ..," which seems fine with respect to the core idea embedded in the prompt. There may still be stray elements that linger here and there in the texts in Phase 4, but overall, everyone seemed to have gotten the point.

\section{Discussion}

The asynchronous activity was a means to observe the contribution of sociocultural and technological factors in terms of cognitive development of participants. I based my inquiry on two elements: the performance of participants as a group, and a scrutiny of individual performances based on selected texts to see how their views on the issue have evolved over time. There are a few abbreviations that often redirect the reader to information sources. Please note how they should be read.

A.A-1: Appendix A, text 1 (Same for A.C-2, A.D-2)

R.I-A: Results, part I, rubric A

R.II-B.1: Results, part II, rubric B, statement 1

R.III-A.1: Results, part III, section A, statement 1

R.IV-A.2: Results, part IV-rubric A, statement 2

\section{A. Performance of the group as a whole from Phase 1 to 4}

A count of thematic units over the two phases made it possible to compare and contrast them. Let us recall that central ideas that appear in the texts of the write-ups were referred to as rubrics or thematic units. Further, let us also recall that the central query was about "problematizing a situation" in view of designing a course in the domain of ESP, which is understood as investigating the context to fix one's opinion about who and what are the sources of information to assess in order to design a course. Phase 1 listed ten rubrics, most of which were unconnected to the task of concern. For instance, rubrics such as $\mathbf{B}, \mathbf{E}$ and $\mathbf{I}$ show that participants just took a chance in.

B. The Nature and definition of ESP

F. Origin of ESP

I. Learners expertise in the field to value

Then even though C, D, F, G and J (e.g., C: Issues Relating to the content of an ESP course [Language use, function and skills]; D: ESP methodology: Learner-centered; functions and skill-centered; An approach 
to ELT,[also see R.I-F,G, \& J, p.8]) are related to a course design, they were not relevant then. In fairness, thematic unit " $\mathrm{A}$ " (reconnaissance, investigation and need assessment) is the only one that addressed the core issue. In a scatter plot projection of rubrics of Phase 1, all the unconnected ones would be featured as outliers, which shows a dispersion from the base.

On the other hand, 2 major rubrics emerged in Phase 4 write-ups, one of which included two subthemes: Problematizing a situation is tantamount to 1) investigating it and then 2) Using data to design the course (p.11). The shrinking of rubrics from 10 to 2 would tend to show that there were less disparate views from the central issue in Phase 4. In other words, there was more agreement among participants. In fact, to the exception of one, that brought about collateral ideas again (e.g., methodology, outcome of ESP), no other write -up in phase 4 contains unconnected ideas or loose statements, strictly speaking. This seems a clear evidence of development which is the result of learning made possible within the learning community where multifarious assistance was available.

The disparity in terms of thematic units count between the write-ups of the two phases also highlights the concept of activity in the completion of task. Activity theory has it that the ferment of activities is located in "particular goals, motives and sociocultural histories" (Roebuck, 2000, p. 26) at a given point in time (also see Lantolf \& Thorne, 2009). Therefore, though learners may engage in the same task, activities, viewed as human idiosyncratic practices at the core of the process of development (Kuuti, 1996) are necessarily different from one individual to another.

\section{B. Comparing individual performance of some participants over the two phases}

The results of the microanalysis of write-ups from Phase 1 showed that the participants did not actually address the question. Instead, in various ways, they mentioned things that are related to ESP, but unconnected to the question $(\mathrm{N}=2)$, or they hedged throughout the text $(\mathrm{N}=2)$. One participant among the five was literally astray (Appendix A-1,2,3,4 \& 7 or Results IV-B, p.11 for more information).

Dissimilarly, the analysis of the texts from Phase 4 write-ups shows more convergence among the texts. Besides other considerations they included essential concepts or rubrics such as 'problematizing is about investigating' and that 'needs analysis was crucial' or the course design is dependent on 'the right data' (Appendices B text 2, C text $2 \& \mathrm{D}$ text 2)

The texts of the write-ups in Phase 4 are sharper and more relevant in terms of the central thinking that is expected to be an acceptable answer to the query. All this indicates that a dramatic change has occurred in terms of the views and understanding of the question. In other words, the authors of these texts have gained substantial learning in the process of the activity. Therefore, there has been a form of development, from people who did not know to some who do now.

The two instances that allowed for gauging the outcome of the asynchronous activity, that is to say the overall performance of participants' output as a group, and the study of the individual performance of some selected people over Phase 1 and 4, have unequivocally pointed to some cognitive gains. This calls for a few comments. 
It is noteworthy that the orientation of the task required that everything be put on the table (The platform of the common e-mail box) for everyone to see, think about and reflect upon, such as write-ups, critiques, concepts, notions, ideas, and viewpoints, besides other considerations. Thus participants could not but talk and listen to one another, if they were serious about completing the task ("The way the activity was organized made people interact. So it encouraged collaboration between among us" [R.III-A.1.a, also see ' $\mathrm{b}$ ']). In fact, there were real needs to meet, both at the notional and conceptual level in order for them to accomplish the task, such as understanding what 'problematize' connotes; constraints on the tasks, i.e., "This task is not about the historical development of ESP. What does problematizing means? This is what we are concerned with" (R.II-A.6; also see '1' and '2').

As the asynchronous activity was up and running, interactions that ensued became need-based intercourses where care, attention and interests got heightened, which increases motivation ("The online activity was helpful in many ways, especially it created a kind of confidence and motivation in me which I do not usually have. So it helped me learn more than in classroom," R.III-A.5.b). No surprise that, at various moments of the task, participants committed and willed to contribute wholeheartedly, on one hand, and to be receptive to other's views, opinions, critiques, on the other ( "Generally speaking, from the second step of the online assignment the activity was very exciting in terms of sharing and discussing our views." (R.III-A.1.d). All of the foregoing lead to everyone being engaged in intense exchanges reflective of real life communication which turned the bulk of participants into a community of practice ("This activity makes everyone active participant because it gives everyone a space to have their say" [ R.III-A.1.e]). Then, in the process the community of practice instilled a learning spirit into the group, something largely conducive to turning the participants into a learning community ("We learn from our peers since we have the possibility to compare our work and improve ourselves" [R.III-A.2.a]; also see 'c' \& 'd') .

By dint of sustained collaboration, the community of practice eventually transformed the asynchronous activity into a learning environment (R.III-A.1-5, pp. 9-10). In fact, many participants acknowledged that the activity was very informative and that they had learned much by giving and taking (R.III-A.2)

This learning environment actually was a social ecosystem, a sociocultural framework where learning occurred through the dynamic synergy of peer teaching, during which they operated within each other ZPDs ("I found it very interesting to get engaged in this online activity. From the second stage, the reactions of the members of my group helped me sized my understanding of the ESP course design issue" [R.III-A.2.e]). In a sense, this framework portrayed key ingredients of social intercourses - those who knew at a given point in time, the 'More knowledgeable Ones' (MKO) or 'Experts' ("This task is not about the historical development of ESP. What does problematizing means? This is what we are concerned with" (R.II-B.6), and those who did not know, the 'novices' ("Rick's 'relevant questions' that allow for problematizing the overall situation help me understand the question" (R.II-C.1). Here the speaker is the novice while Rick is the expert. However, in a complex and dynamic tandem, these roles were variably distributed among peers in time according to circumstances. In fairness, they all were novices at one time or/and experts at another ("Each of us had to say something in order to put our classmates on the 
right way because we did not have the same perceptions and the same way of understanding things. This particularly helped me a lot" (R.III-A.1.b ).

The pronouncements made by participants render an account of essential sociocultural factors that came into play during the asynchronous activity. This precisely reflects the sociocultural dynamics through which socialization processes, including language and development are achieved.

The learning community that was set up through the activity leaned on a number of affordances (van Lier, 2000) or occasions (Swain \& Lakpin, 1998)- any stimulating or helping occasion or opportunity or fact that could be improved to boost the activity. This fall into two major categories: explicit and implicit ones. The explicit ones were mainly, for instances, those voiced by the participants such as online sources (the many contributors that are out there, dictionaries, various views or opinions on given topics, hyperlinks, examples of knowledge application, ("I was able to use other online resources, such dictionaries, translate from google to improve on my write-up" [R.III-A.3b]).

The implicit ones are those that one is not often aware of. Such ones include, for instance the 'virtual world itself'. Participants appreciated the fact that they were free from cumbersome presences -the instructor or their classmates who often become, intrusive, obtrusive and intimidating ("It also helps us to do our exercises freely without the presence of a supervisor" [R.IV-A.4a]). This is an affordance that increased learners' engagement and collaboration among peers. Other implicit affordances are "motivation," "confidence," "self-reliance," and "critical thinking"(R.III-A.5 b \& c). In addition, the online activity is said to be "less stressful" ("It is less stressful, so I feel motivated" [R.III-A.5 d]). These powerful affective components are often predictive of learning. That is why lot of time and energy are often invested in order to instill them within the population of learners.

Furthermore, the many questions, contradictions, disagreements, pertinent or impertinent statements or comments that were manifested during social discourses and which engaged any form of process likely to be conducive to noticing any form or type of knowledge may bear the status of affordance. In short anything that was incidentally used or came in handy to aid the completion of the task.

Affordances are environmental components in an ecosystem, like a classroom, online tasks or activities. Therefore, the contributions of all the above mentioned factors were ecological supports for the project. Therefore, participants in the asynchronous activity were comparable to the solitary traveler in an unchartered territory. Survival depends not only on instinct, but also on the ability and intelligence of the individual to make a selective use of the elements of the environment with contingency and parsimony. The concept of "learner as agent" which is underscored here is also at the heart of the ecological approach to learning, in general.

\section{Concluding remarks}

The relevance of this topic, "Information Technology Integrated Education, a hard road to travel for lame ducks: Blended instructional delivery, potentials for learning affordances for ELT 
students, Université Felix Houphouët Boigny, Côte d'Ivoire" stands out. For despite the dire situation of our educational system in terms of environmental factors such as issues relating to technological hardware, software and particularly quality networking connectivity, there were ways out to attempt to implement a form of technology integrated education. Further, this study has shown that there are a number of indications that online tasks may turn out to be a worthy supplement to teacher-fronted instruction in educational contexts where time is not yet ripe for partial or full online instruction.

The findings of this study have proved empowering to me, which is why I believe that educational communities in systems similar to mine should be encouraged to try, ever so little, to take advantage of whatever form of technological advances that are locally available, in order for them to serve the best interests of their learners. Any form of integration, whatsoever, is better than no integration at all.

\section{Conclusion}

My intention in this study was to examine ways out for the implementation of more innovative pedagogies in instructional endeavors, from the perspective of an ecological approach to the teaching-learning process. Given the magnitude of advances in the newer means of communication, I thought there was room to shift the aim in our traditions of doing business. Thus, the following questions begged for answers: What types of technologies, on the one hand, and what applications of these technologies on the web, on the other, could be integrated in instructional deliveries? What could be hoped for students learning wise?

I decided to observe the contribution of sociocultural and technological factors in the cognitive development of participants engaged in an asynchronous activity on the web. A multilayered investigation was carried out by means of corpora built up at various stages of the study and which helped generate invaluable data. The conclusions of the investigation suggest that there are substantial cognitive gains from online activities. This has already been underscored in a number of studies (Anderson \& McGreal, 2012; Singh \& Reed, 2001; Xu, 2016)

New technologies of communication offer an opportunity to capture new pedagogies that reflect the requirements of modern times. In addition, given that they are replete with affordances, they allow for setting in motion learning approaches that reflect natural approaches to socialization, including language socialization of the individual, such as an ecological approach.

The asynchronous activity broke the secular barriers embodied in the traditional educational models, with the teacher at the center as The absolute font of knowledge. This activity, in contrast, reflects the model of learning of the mother tongue, where there is no room for artificiality, nor the objectification of language learning. An ecological approach to foreign and second language education emphasizes the fact that we should let nature take control over the learning process. And in this framework, as the learner pursues knowledge, which is at the same time a social, environmental, and an idiosyncratic act, he is also engaged in the discovery of the self and the surrounding world. In so doing, he uses his logico-mathematic and emotional intelligence, discriminating at will and committing knowingly, which builds his capacity and empowers him. 
I firmly believe that despite the present structural deficiencies that impede the use of the web, a little dose of creativity coupled with a real desire and commitment will build the momentum conducive to an implementation of blended instruction formats to boost foreign language education, in particular. Education is often likened with a skein to disentangle because it is like aiming at a moving target (Dewey, 1937). It comes as no surprise that the community of educators always seem in an endless quest of their marks. The ecological approach is a further attempt in this line of thinking.

Good task orientation that would allow for full, rich and real like-like intercourses among learners mediated by language is key to the implementation of an ecological approach to foreign or second language education. No model has been clearly defined as yet, to the best of my knowledge that is why this approach is not for faint-hearted people, but rather for those willing to take the trouble for the benefits of better educational outcomes.

\section{References}

[1] Acquisition and socialization. In P. A. Duff \& N. H. Hornberger (eds.) Encyclopedia of Aimin, L. (2013). The Study of Second Language Acquisition under Socio-cultural Theory. American Journal of Educational Research, 1(5), 152-167.

[2] Anderson, T. \& McGreal, R. (2012). Disruptive Pedagogies and Technologies in Universities. Educational Technology and Society, 15 (4), 380-389.

[3] Behroozizad, S., Nambiar, R. M. K., \& Amir, Z. (2014).

[4] Berge, Z. L. (2001). The Context of Distance Training. In Z. L. Berge (Ed.), Sustaining Distance Training, PP 3-12. Jossey-Bass. San Francisco, CA.

[5] Breen, M. P. (2006). Collegial development in ELT: The Interface between Global Processes and local Understandings. In S. Gleve \& I. K. Miller (Eds.) Understanding the Language Classroom. Basingstoke, Palgrave McMillam, 200-225.

[6] Canagarajah, A. S. (2002). Reconstructing local knowledge. Journal of Language, Identity, and Education, 1, 243-259.

[7] Castle, S. (2010). An Analysis of Student Self-assessment of Online, Blended, and Face-to-face Learning Environment: Implications for Sustainable Education Delivery. International Education Studies, 3 (3). Retrieved on October 5, 2016 from http://works.bepress.com/cgi?article=1016\&context-chad_mcguire

[8] Dewey, J. (1937). Logic: The theory of inquiry. Wiley. New York, NY.

[9] Donnelly, D., McGarr, O., \& O'Reilly, J. A Framework for Teachers 'Integration of ICT into their Classroom Practice. Computer and Education, 57, 1459-1483.

[10] Ellis, R. (1994). How culturally appropriate is the communicative approach? ELT Journal, 50(3), 213-218.

[11] Freire, P. (1997). Pedagogy of the oppressed. Continuum. New York, NY

[12] Freire, P. (1997). Pedagogy of the oppressed. Continuum. New York, NY.

[13] Gilthrow, J., \& Colhoun, E. R. (1992). The culture of power: ESL traditions, Mayan resistance. In B.Burnaby \& A. Cumming (Eds.), The socio-political aspects of ESL (pp. 50-66). Toronto, Ontario.

[14] Halliday, A. (1994). Appropriate methodology in social context. CUP. Cambridge.

[15] Hopper, P. J. (1998). Emergent Grammar. In M. Tomasello (Ed.), The New Psychology of Language: Cognitive and Functional Approaches to Language Structure. Lawrence Erlbaum. Mahwah, NJ.

[16] Kramsch, C. (2008). Ecological Perspectives on Foreign Language Education. Language Teaching, 41(3), 389-408. 
[17] Kramsch, C. J. \& Steffensen, S. V. (2008). Ecological perspectives of second language Kumaravadivelu, B. (2003b). Critical language pedagogy: A postmethod perspective on English language

[18] Kuuti, K. (1996). Activity Theory as a Potential Framework for Human-computer Interaction Research. In B. A. Nardi (Ed.) Context and Consciousness: Activity theory and Human-computer Interaction. MIT Press. Cambridge, MA.

[19] Language and education. 2nd Edition. Vol.8. Language Socialization, 17-28 . Springer

[20] Lantolf, J. (Ed.). (2000). Sociocultural theory and second language learning. New York: Oxford

[21] Lantolf, J. P. \& Thorne, S. L. (2009). Sociocultural Theory and the Genesis of Second Language Development. OUP

[22] Larsen-Freeman, D. (1999, October). On the appropriateness of language teaching methods in language and development. Paper presented at the Fourth International Conference on Language and Development, Hanoi. Retrieved November 14, 2016 from http://www.languages.ait.ac.th/hanoi_proceedings/ larsen-freeman.htm

[23] Larsen-Freeman, D. (2000). Second Language Acquisition and Applied Linguistics. Annual Review of Applied Linguistics, vol. 20, 165-181

[24] Larsen-Freeman, D. (2007). On the complementarily of chaos/complexity theory and dynamic systems theory in understanding the second language acquisition process. Bilingualism: Language and Cognition, 10(1), 35-37

[25] Lim, D. H., Moris, M. L., \& Kupritz, V. W. (2007). Online vs. Blended Learning: Differences in Instructional outcomes and Learner Satisfaction. Journal of Asynchronous Learning Networks, V. $11(2), 27-42$.

[26] Mahmoodzadeh, M. (2012). Toward an Understanding of Ecological Challenges of Second Language Teaching: A Critical Review. Journal of Language Teaching and Research, 3(6), 1157-1164.

[27] Martin, F. (2011). Computational Aspect of Lexical functional Grammar. Language and Linguistics Compass, 5(1), 1-18

[28] Miles, M. B. \& Huberman, A. M. (2004). Qualitative Data Analysis (2 ${ }^{\text {nd }}$ Ed.). Sage. Thousand Oaks, CA.

[29] Nishino, T. (2008). Japanese secondary school teachers' beliefs and practices regarding communicative language teaching: An exploratory survey. JALT Journal, 30(1), 27-50.

[30] Ohta, A. S. (2001). Rethinking Interaction in SLA: Developmentally appropriate assistance in the Zone of Proximal Development and the acquisition of L2 grammar

[31] Pica, T, Kanagy, R. \& Falodun, J. (1993). Choosing and using communication tasks for Second Language instruction and research. In G. Crookes \& S. Gass (1993a) (Eds.) Tasks and Language Learning: Integrating Theory and Practice. Multilingual Matters

[32] Reece, M. \& Lockee, B. (2005). Improving Training Outcomes through Blended Learning. Journal of Asynchronous Learning Networks, 9(4), 49-57.

[33] Richards, J.C. \& Renandya, W. A. (2002). Methodology in Language teaching: An Anthology of Current Practice. CUP

[34] Roebuck, R. (2000). Subjects speak out: How learners position themselves in a Psycholinguistic Task. In J. P. Lantolf (Ed,).Sociocultural Theory and Second Language Learning. OUP

[35] Saussure, F. de (1966). Course in general linguistics. McGraw-Hill, New York. Science \& Business Media

[36] Singh, H. \& Reed, C. (2001). A White Paper: Achieving Success with Blended Learning. ASTD State of the Industry Report. American Society for Training and Development. Alexandra, VA.

[37] Swain, M \& Lakpin, S. (1998). Interaction and Second Language Learning: Two Adolescent French Immersion Students Working together. The Modern Language Journal, 83, 320-338. teaching. World Englishes, 22, 539-550. 
[38] Tomasello, M. (2003). Constructing a Language: A Usage-Based Theory of Language Acquisition: Harvard University Press. Cambridge, MA.

[39] Van Lier, L. (2000).From Input to Affordance: Social-interactive Learning from an Ecological Perspective. In J. P. Lantolf (Ed.) Sociocultural Theory and Second Language Learning. OUP

[40] Van Lier, L. (2004). The Ecology and Semiotics of Language Learning: A Sociocultural Perspective. Kluwer Academic. Dordrecht

[41] Van Lier, L. (2004). The Ecology and Semiotics of Language Learning: A Sociocultural Perspective. Kluwer Academic. Dordrecht.

[42] Vygotsky, L. S. (1978). Mind and Society: The Development of Higher psychological Processes. Harvard University Press.

[43] Whitehead, A. N. (1929). The aims of education and other essays. The Free Press. New York.

[44] Whiteside, A. (2007). We are the explorers: transnational Yucatec Maya-speakers negotiating multilingual California. Ph.D. dissertation, University of California, Berkeley

[45] Wiersma, W. (2001). Research Methods in Education: An introduction, 7th edition. Allyn \& Bacon. Boston, MA

[46] Xu, A. \& Chen, G. (2016). A Study of the Effect of Teachers' Information Literacy on Information Technology Integrated Instruction and Teaching Effectiveness. Eurasia Journal of Mathematics, Sciences and Technology Education, 12 (2), 335-346.

[47] Yates, R. and Muchisky, D. (2003), On Reconceptualizing Teacher Education. TESOL Quarterly, 37, 135-147.

*Corresponding author.

E-mail address: sidiara@yahoo.fr

\section{APPENDIX A}

1) (Crocozi) I agree with this statement to the extent that an ESP class is all about course design. In fact, it serves as guide for the ESP course designer. In other words, course design is what allows shedding light on the different procedures coming into play for a successful ESP class, including the aims, its specific objectives, the teaching supports, the lesson plan, as well as the evaluation. As such, it is clear that it really problematizes an ESP situation for the sake of success. One can even assert that an ESP class without course design is impossible.

2) (Titipo) In ESP, course design is problematizing in the sense that, at the end of the course; the teacher may be sure that learners could be operational in their specific domain; they could use English to do their job. The teacher may be convinced that he reaches the ultimate goal; and this issue calls for a certain numbers of elements: the selection of appropriate materials, the objective of the course, design suitable syllabus, otherwise it is impossible to reach the goal.

3) (Crocoza) English for Specific Purposes aims at training learners for them to be efficient in their field of work. This should be done in an organized manner which the course design is containing everything the trainer has to do. But he has to proceed by asking questions. Jeremy Day said the needs analysis is at the heart of course design. Only after that a good outcome can be expected.

4) (Yawolo) ESP course design is problematizing a given situation for reaching an outcome in the sense that ESP is more focus on language in context than on teaching grammar and language structures. In fact, its definition: English for Specific Purpose lets us understand that, the learner must approach the study of the target language through a field that is already known and relevant to him. Thus, he will be motivated and learn more. And consequently he will be able to use the target language he has learned in his work or professional domain. 
5) I agree with this assertion because when individuals call you for an ESP course they have some needs, certain deficiencies bound to their work area to be filled. So this situation becomes a challenge for the trainer, a problem to be solved in a sense that he must collect data about trainees needs and their managers expectations to know exactly, what appropriate materials, activities, tasks, method to be included in the course. All this to meet their needs, satisfy all the parties and achieve successfully the course goals.

6) Course design in ESP requires solving a problem to the extent that the teacher may not know about the content subject, the appropriate competences to be developed and materials to be used. In so doing, he should make investigations as much as possible, even beyond a needs analysis so that his course design suits learner's specific needs, hence his role of researcher. In this perspective, I agree with that statement.

7) (Alisto) As far as ESP aims at equipping learners with the appropriate tools that help them be effectively operational in their domain with the English language, the ESP course designer is in charge of finding suitable materials, methods and learning tasks according to the specific needs of his learners. It therefore appears that course design in ESP addresses the issue of what should be taught and how it is made in order for learning to occur effectively.

8) Problematization in ESP course design calls for where to begin, why, how and what content as well as material should the ESP teacher use to satisfy the current work-related needs of the learners. More importantly for honoring the desires of all the parties engaged in the training. In order words, target situations shape the problematization through which the teacher will go in order to reach the ultimate goal. Therefore, we can say that without a deeper problematization of a given situation it is impossible to reach any goal

9) I think course design in ESP is really about problematizing a given situation in order to achieve successful end. In fact ESP course design refers to a planning of a course to achieve needed goals. Since ESP itself is defined to meet specific subject matters taking into account learner's need, it is important to know why a given learner needs to learn English language. Because this awareness of the need of learners influence the way course will be designed in order to allow learner to be efficient at the end of the training. then, finding the mean to allow learner to achieve better in his field of activity become a uppermost question for a teacher who must be able to design the right ESP course for a best training. 
[Diarassouba *, Vol.5 (Iss.1): January, 2017] ICV (Index Copernicus Value) 2015: 71.21

APPENDIX B
ISS- 2350-0530(O), ISS- 2394-3629(P)

IF: 4.321 (CosmosImpactFactor), 2.532 (I2OR)

InfoBase Index IBI Factor 3.86

After reading the works of the I members of mi groups, it is clear that in EST, Course designers have to solve a lot gi preoccupations in order to a chaise successfully. These preoccupations can le how to find a good material, lesson on activities to really meat the needs of their learners.

1

The reactions of the other members of my on line group work reinforced the Knowledge I howe about ESP. We all agree on the fart that an ESP course designer should above all inventioute in order to hove a clear cut idea of the learners' needs. By doing so, hel she proslematizes a given situation.

(2)

2

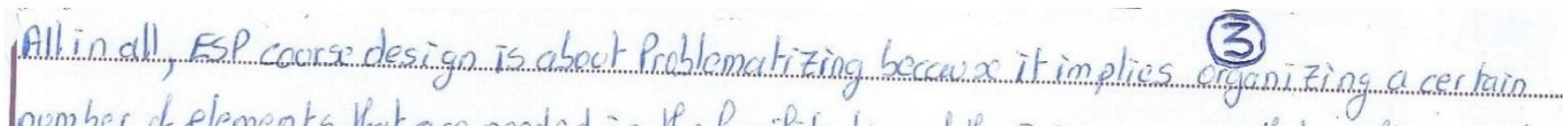
number of elements. that are needed in the facilitation the Esp course and hat might gur ide the

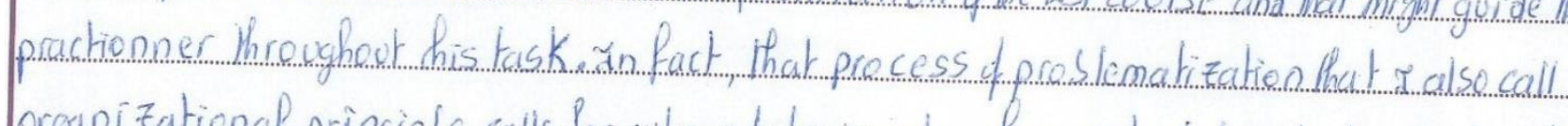
organizational principle calls for where to begin, why, haw, and what content and materials

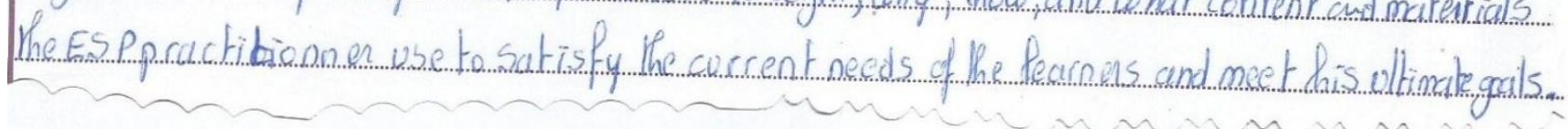

3

Designing a suitable course design for a specific group p of earners, requires on the part of the trainer to know the lacks, the target needs, aud the born ing nouns of learners through a through

(4)

4

Http://www.granthaalayah.com C International Journal of Research - GRANTHAALAYAH

[352] 
[Diarassouba *, Vol.5 (Iss.1): January, 2017]

ICV (Index Copernicus Value) 2015: 71.21
ISBN- 2350-0530(O), ISBN- 2394-3629(P)

IF : 4.321 (CosmosImpactFactor), 2.532 (I2OR)

InfoBase Index IBI Factor 3.86

APPENDIX C

From what I learned from my freinds, I think that the investigate design is problematic for it Calls $f(1)$

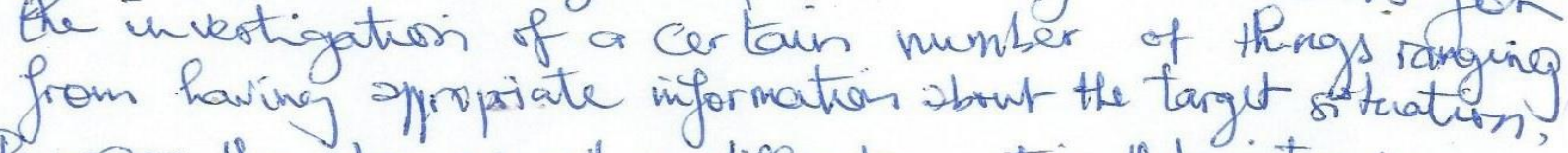
Learners themselves as well as different parties that intervene.

1

Course Design in ESP is about problematizing a given situation ts meet proceonoful and to the extent that ESP is yo al directed a learner-centered (2) Indeed, ESP call for short -term achievement, no that, teacher should-mastes the oology of levering. He should answer the following auctions: who is the learners? what to integrate in the programs?, what in the teaching context? and what is the time?

2

As ESP Cow design is a reflexive proven of wish at to do and how to do it in ouch. a way that learner will appropirate the required language skills, knowledge, and attic dens so that than will perform weill in their professional domain: the course. designer must know his learners needs or Morons for learning English, their

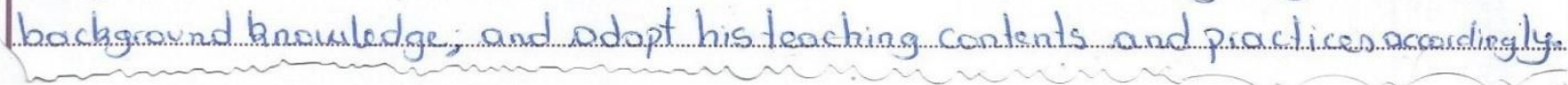

3

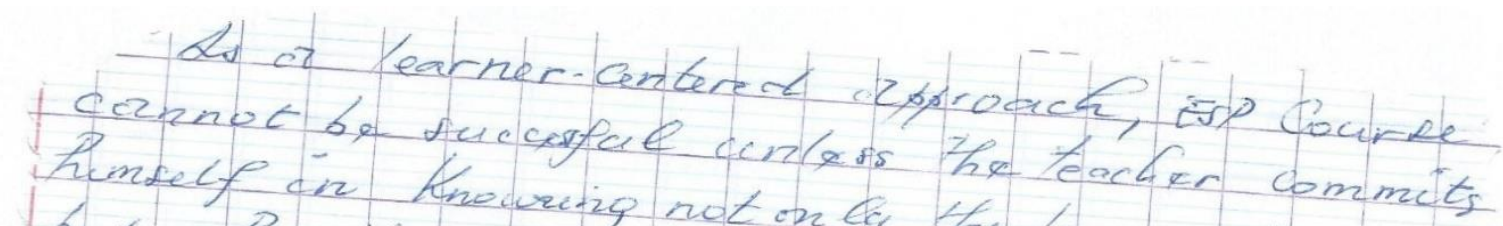

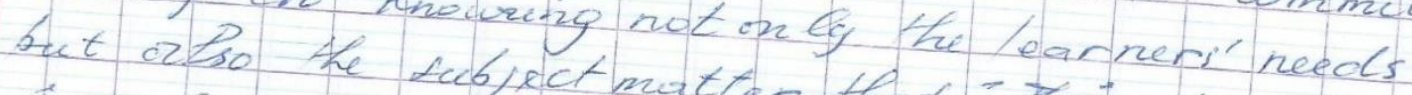

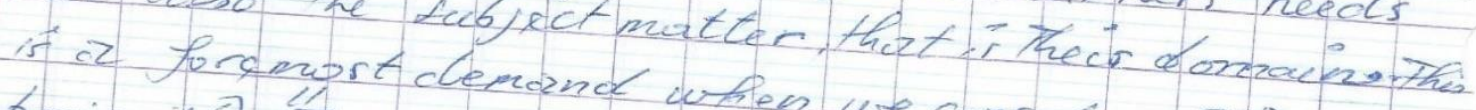

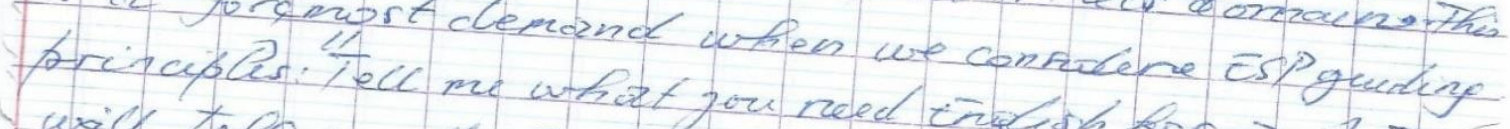
wide tell you the english that you need (4) \&

4

Http://www.granthaalayah.com @International Journal of Research - GRANTHAALAYAH

[353] 


\section{APPENDIX D}

After reading my frients reactions, I do confeis I have now a uliden scope and better underslanding gabout course desugn. I agree with imflement the syllabers in order to achieve a sucessful end. I agree with my frients (Bintou, Adito) beceuse they sall sagree son the fact thaet succepful end. On nusoun, I retain that it is essentira to problematize the situration because it previstes us all sat a that we need to satis yoult the jartiog

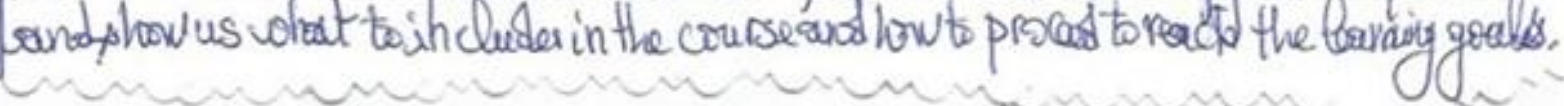

2

The commen idea Thut emenges from iny juent notes is that Ceurse deogin in EsP is not implentonted Withut specifying the cintent in which the Redrnearall (3)

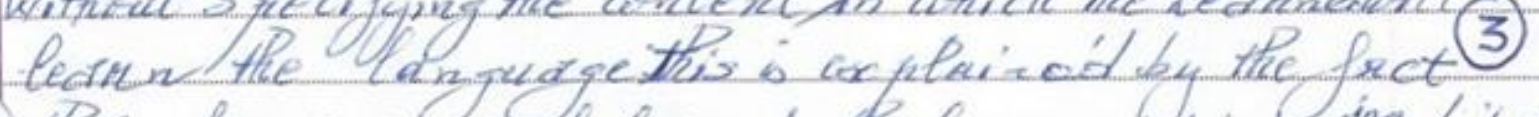

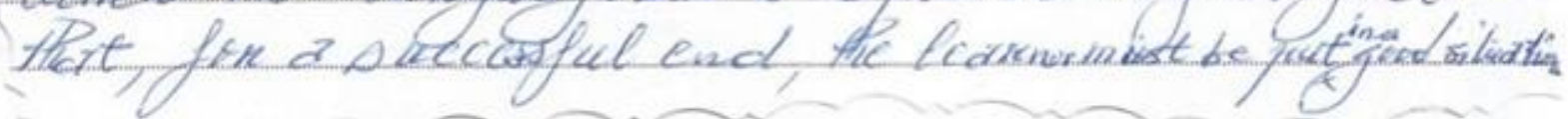

\section{3}

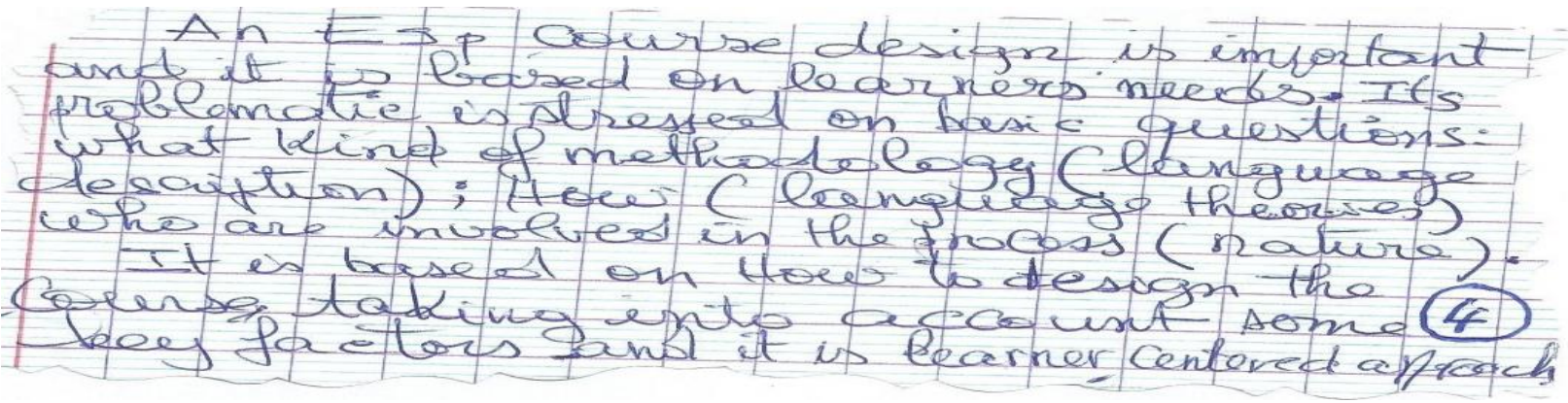

